\title{
Prediction of Temperature Development in Concrete using Semi-adiabatic Temperature Measurements
}

\author{
W.M.T.D. Wasala and H.D. Yapa
}

\begin{abstract}
Temperature development in concrete is caused by the heat of hydration which can be measured using calorimetric methods. In this study, a semi adiabatic calorimeter test was used first to measure the temperature development in six distinct C35A concrete mixes, and then using a heat loss compensation method, adiabatic temperature rise profiles were predicted. Cement and fly ash quantities in the mixes were varied to study the variations of the temperature development. The study then developed a two dimensional temperature prediction model applicable to rectangular concrete elements, based on heat transfer equations associated with the Fourier equation. A Finite-difference discretization was used in the modelling. The model took into account the heat generation due to cement hydration, heat transfer within the concrete element, and heat interactions between the concrete element and its environment under various boundary conditions. The prediction model has the potential for making two-dimensional temperature predictions in mass concrete at varying times and locations. Finally, the temperature prediction model was used as a case study to study the temperature development in a concrete wall. The results highlight the possible influences of concrete thickness on the internal temperature development of concrete and how the temperature could be controlled by using appropriate concrete mixes.
\end{abstract}

Keywords: Adiabatic temperature, C 35A concrete, Heat loss compensation

\section{Introduction}

Concrete is the most widely used construction material in the world. It is primarily a composite of cement, aggregate and water. Cement hydration is an exothermic reaction which releases up to 500 joules of heat per gram of cement [Neville and Brooks 1987]. The thermal conductivity of concrete is relatively low. Thus, at the early ages, particularly in thick concrete segments, temperature variations across the structure can take place. As a consequence, thermal strains and stresses can develop resulting in undesirable cracking. Therefore, prediction of the internal concrete temperature and implementation of appropriate measures to mitigate excessive cracking become important.

Concrete is widely used to construct waterretaining structures that need to be durable and impermeable throughout their design lives. Hence, crack control in concrete water retaining structures is important more than in any other concrete structure. The desirable maximum crack width conforming to BS 8007is $0.2 \mathrm{~mm}$ and it can vary from $0.05 \mathrm{~mm}-0.2 \mathrm{~mm}$ conforming to Eurocode 2. It is recommended to use Grade 35A (C35A) concrete for such structures due to the low permeability and low heat of hydration of that particular grade of concrete. The scope of the current study was to predict the temperature development in C35A concrete.
The specifications for C35A concrete require it to have a minimum cement content of $325 \mathrm{~kg} / \mathrm{m}^{3}$; a maximum cement content of $400 \mathrm{~kg} / \mathrm{m}^{3}$ for OPC or cement containing Ground Granulated Blast-furnace Slag (GGBS); or $450 \mathrm{~kg} / \mathrm{m}^{3}$ for cement containing Portland Pulverized Fuel Ash(PFA) and a maximum water/cement ratio of 0.50 for OPC concrete and 0.55 for PFA concrete [BS 8007]. More detailed specifications of $\mathrm{C} 35 \mathrm{~A}$ concrete are given in BS 8007.

Various test methods such as the heat solution method, adiabatic calorimeter method, and semi-adiabatic calorimeter method are available to measure the heat of hydration and the resulting temperature rise of concrete. The semi-adiabatic calorimeter method is a relatively cheap and a not so complex option. The current study therefore investigated the temperature development in C35A concrete using the semi-adiabatic experimental method.

Eng. W.M.T.D. Wasala, MIE(Sri Lanka), B.Sc. Eng. (Peradeniya), M.Eng. (Peradeniya), National Water Supply and Drainage Board.Email:rajakaruna1984@gmail.com

Eng. (Dr.) H.D. Yapa, AMIE(Sri Lanka), B.Sc. Eng. (Moratuwa), Ph.D.(Cantab), Department of Civil

Engineering, University of Peradeniya.

Email:hiranyapa@gmail.com 
The semi-adiabatic behaviour of several C35A concrete mixes was assessed experimentally. The semi-adiabatic temperatures were then converted to adiabatic temperatures, and the latter were used to predict the temperature in hardening concrete. Heat conduction in the hardening concrete was determined from the transient heat balance which is governed by Fourier's law [Holmen 1986]. Thereby, a temperature prediction model associated with two-dimensional heat transfer and finite difference method was formed.

The proposed temperature prediction model can be used to predict the temperature rise of regular shape concrete elements and to study the sensitivity of various associated parameters to temperature development.

\section{Heat Transfer and Temperature Development in Concrete}

Temperature development in concrete elements is governed by heat of hydration of cement and heat dissipation. The former is primarily a matter of mix proportions whilst the latter depends on properties such as thermal diffusivity of concrete, thermal characteristics of the formwork and the environment. Hence, the concrete temperature will depend on the constituent materials, geometry, formwork type and environmental/boundary conditions. Thus, temperature prediction of a concrete member is complex [Ballim 2004, Kyle et al. 2006].

\section{Heat Transfer Analysis}

Heat transfer in concrete can be described using the Fourier equation [Holmen 1986]. The relationship in three dimensional (3-D) form is,

$$
\rho C \frac{\partial \mathrm{T}}{\partial \mathrm{t}}=\frac{\partial\left(k_{x} \cdot \frac{\partial \mathrm{T}}{\partial \mathrm{x}}\right)}{\partial \mathrm{x}}+\frac{\partial\left(k_{y} \cdot \frac{\partial \mathrm{T}}{\partial \mathrm{y}}\right)}{\partial \mathrm{y}}+\frac{\partial\left(k_{z} \cdot \frac{\partial \mathrm{T}}{\partial \mathrm{z}}\right)}{\partial \mathrm{z}}+\frac{\partial \mathrm{Q}}{\partial \mathrm{t}} \ldots
$$

where $\rho, C, T, Q, k$ denote the density, specific heat, temperature, internal heat evolution and thermal conductivity of the concrete respectively while $x, y, z$ denote the global coordinate system and $t$ is the time. Since direct solutions for heat transfer in concrete are complex, it is necessary to use numerical analysis based approaches [Ballim 2004].

\section{Semi-adiabatic Temperature Measurements}

\subsection{Concrete Mix Design}

Six distinct C35A concrete mixes were designed by varying the amount of cement, fly ash and admixture. The mix proportions were calculated using the ACI method of concrete mix design [Neville and Brooks 1987]. The mixes were such that there were considerable differences in their heat dissipation. The design criteria were as follows:

Mix 1 was the control mix which contained only OPC. Since fly ash releases a lesser amount of heat than OPC, to have a lower heat evolution than Mix 1, Mix 2 and Mix 3 were formed by replacing $20 \%$ and $35 \%$ of OPC in Mix 1 respectively with Class F fly ash. In order to have a lower OPC content and thereby a lower heat relative to Mix 1 , a water reducing admixture was used for Mix 4. To observe the impact of using the water reducing admixture on the heat dissipation characteristics, Mix 5 was designed by adding the admixture to the proportions in Mix 1. The design for Mix 6 was such that it comprised of OPC, 20\% fly ash, and the admixture. Hence, Mix 6 was a combination of Mix 1, Mix 2 and Mix 4 and contained the lowest amount of OPC amongst the mixes. The target slump for all the mixes was $80 \mathrm{~mm}$. The mix proportions used are tabulated in Table 1.

Mixtures from Mix 1 to Mix 6 are denoted as M1-C, M2-C-F-20, M3-C-F-35, M4-C-A-1, M5-CA-2, and M6-C-A-F-20 respectively.

Table 1 - Concrete mix proportions for $1 \mathrm{~m}^{3}$ concrete

\begin{tabular}{|c|c|c|c|c|c|c|}
\hline Item & 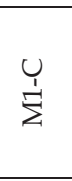 & 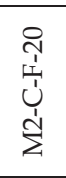 & 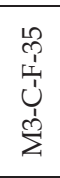 &  & 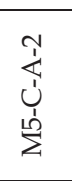 & 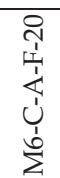 \\
\hline $\begin{array}{c}\text { Cement } \\
\text { (C) } \\
\mathrm{kg}\end{array}$ & 450 & 379 & 353 & 349 & 450 & 294 \\
\hline $\begin{array}{c}\text { Fly ash (F) } \\
\text { kg }\end{array}$ & 0 & 95 & 190 & 0 & 0 & 73 \\
\hline $\begin{array}{c}\mathrm{C}+\mathrm{F} \\
\mathrm{kg}\end{array}$ & 450 & 474 & 543 & 349 & 450 & 367 \\
\hline $\begin{array}{l}\text { Water (W) } \\
\text { kg }\end{array}$ & 202 & 191 & 184 & 162 & 208 & 149 \\
\hline $\begin{array}{l}\text { Coarse } \\
\text { agg. } \\
\text { kg }\end{array}$ & 1000 & 998 & 998 & 997 & 997 & 997 \\
\hline $\begin{array}{c}\text { Fine agg. } \\
\text { kg }\end{array}$ & 765 & 742 & 659 & 958 & 760 & 941 \\
\hline $\begin{array}{c}\text { Admixture } \\
\text { L }\end{array}$ & 0 & 0 & 0 & 3.49 & 0.90 & 3.67 \\
\hline
\end{tabular}

Concrete properties at the initial stage were examined and the compressive strength and the thermal conductivity were tested at 28 days. The test results are presented in Table 2. 
Table 2 - Concrete test results

\begin{tabular}{|c|c|c|c|c|c|c|}
\hline Item & $\stackrel{\substack{1 \\
\dot{\Sigma}}}{1}$ & 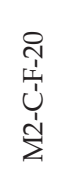 & 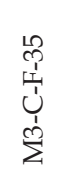 & 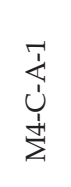 & 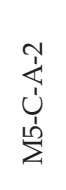 & 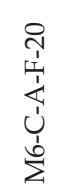 \\
\hline $\begin{array}{l}\text { Slump } \\
(\mathrm{mm})\end{array}$ & 90 & $63^{*}$ & $20^{*}$ & 84 & 161 & $56^{*}$ \\
\hline $\begin{array}{c}\text { Density } \\
\left(\mathrm{kg} / \mathrm{m}^{3}\right)\end{array}$ & 2442 & 2429 & 2408 & 2411 & 2450 & 2416 \\
\hline $\begin{array}{l}\text { Temp. } \\
\left({ }^{\circ} \mathrm{C}\right)\end{array}$ & 27.5 & 28.0 & 26.5 & 26.5 & 26.5 & 26.5 \\
\hline $\begin{array}{l}\text { Comp. } \\
\text { strength } \\
\text { (MPa) }\end{array}$ & 48.0 & 49.5 & 49.0 & 44.5 & 49.0 & 50.0 \\
\hline $\begin{array}{l}\text { Ther. con. } \\
(\mathrm{W} / \mathrm{m} . \mathrm{K})\end{array}$ & 2.52 & 2.52 & 2.53 & 2.47 & 2.52 & 2.38 \\
\hline
\end{tabular}

The target slump was achieved in M1 and M4 whereas the slumps of M2, M3 and M6 were lower than the target. As anticipated, M5 exhibited the highest slump, the mix was formed by merely adding the water reducing admixture to M1 mix.

\subsection{Semi-adiabatic Calorimeter Test}

A semi adiabatic calorimeter was used to measure the temperature rise of each concrete mixture. It consisted of an insulated Rigifoam mould, several thermocouples for measuring the concrete temperature and the ambient temperature. A data logger was attached to the apparatus and the temperature readings were recorded at half an hour intervals.

Figure 1 shows the schematic diagram of the calorimeter. The recorded temperatures are illustrated in Figure 2.

\section{Determination of Adiabatic Temperature Rise}

The semi-adiabatic temperature rise is smaller than the adiabatic temperature rise owing to loss of heat with time. Therefore, a heat loss compensation method of estimating the heat loss is required in order to convert a semiadiabatic temperature profile into an adiabatic temperature profile.



Figure 1 - Schematic diagram of semi - adiabatic calorimeter

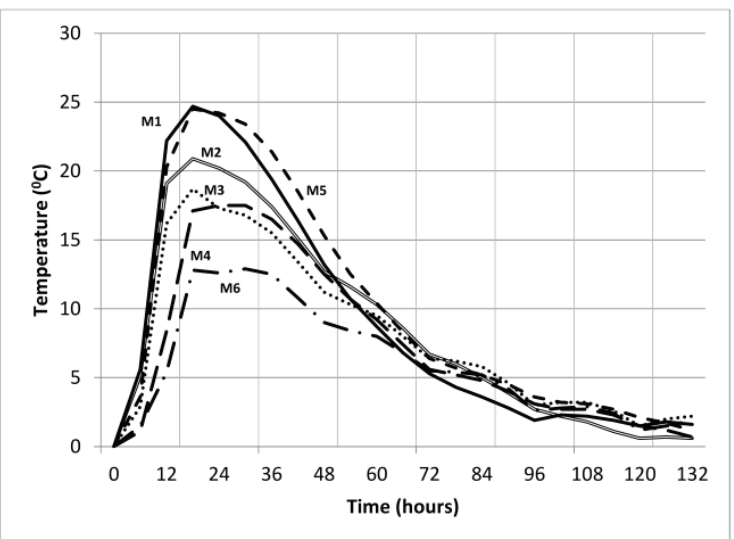

Figure 2 - Semi-adiabatic temperature measurements

As proposed by $\mathrm{Ng}$ etal. [2008], when a concrete volume $V$ is subjected to a semiadiabatic context, the adiabatic temperature rise $T_{G}$ can be expressed as follows with the volumetric mean temperature of concrete represented as $T_{v}$ and the placing temperature represented as $T_{p}$ :

$$
T_{G}-\frac{H_{L}}{v \rho C}=T_{v}-T_{p}
$$

where $H_{L}, v, \rho, C$ denote the amount of heat loss, volume, density and specific heat of the concrete respectively. Considering the heat conducted through the insulating materials [Holman 2010], the heat loss can be expressed as,

$$
\mathrm{H}_{\mathrm{L}}=k \int_{0}^{t}\left(\mathrm{~T}_{\mathrm{s}}-\mathrm{T}_{\mathrm{a}}\right) \mathrm{dt}
$$

where, $k$ is the overall thermal conductivity of the calorimeter; $\mathrm{T}_{\mathrm{s}}$ and $\mathrm{T}_{\mathrm{a}}$ are the surface mean temperatures of the concrete and the ambient temperature respectively. By rearranging Equations (2) and (3), the following equation could be obtained:

$$
T_{G}=\left(T_{v}-T_{p}\right)+\frac{k}{v \rho C} \int_{0}^{t}\left(T_{s}-T_{a}\right) d t
$$

By substituting $\lambda=k / v \rho C, \mathrm{~T}_{\mathrm{G}}$ becomes,

$$
T_{G}=\left(T_{v}-T_{p}\right)+\lambda \int_{0}^{t}\left(T_{s}-T_{a}\right) d t
$$


By differentiating Equation (4), the following equation could be obtained:

$\frac{\partial \mathrm{T}_{\mathrm{G}}}{\partial \mathrm{t}}=\frac{\partial \mathrm{T}_{\mathrm{v}}}{\partial \mathrm{t}}+\lambda\left(\mathrm{T}_{\mathrm{s}}-\mathrm{T}_{\mathrm{a}}\right)$

If the temperature variation across the specimen is very low, e.g., if the specimen size is considerably small, $\mathrm{T}_{\mathrm{v}}$ would be reasonably equal to $\mathrm{T}_{\mathrm{s}}[\mathrm{Ng}$ etal.2008]. In this situation, the temperature at the specimen centre $T_{m}$ can be approximated to represent $T_{v}$ and $T_{s}$, so that $T_{m}=T_{v}=T_{s}$. More accurate values for these two parameters can be obtained by taking several temperature measurements at distinct locations[ $\mathrm{Ng}$ et al. 2008]. However, for the sake of simplicity, the former approach was used in the current study.

$\mathrm{Ng}$ etal. [2008] argued that after a sufficiently long time after placing the concrete (say>120 hrs.), the heat generation becomes considerably small. So fortbeyond 120 hrs., the rate of adiabatic temperature rise would be negligible. Therefore, Equation (6) can be rearranged as follows to determine $\lambda$ :

$$
\frac{k}{v \rho c}=\lambda=\frac{-\frac{\partial T_{m}}{\partial t}}{\left(T_{m}-T_{a}\right)} \quad(\text { for } t>120)
$$

Now, the adiabatic temperature rise $T_{G}$ expressed in Equation (4) can be derived by splitting the testing period into small time intervals $(\Delta \mathrm{t})$ and performing numerical integration as follows:

$T_{G}=\left(T_{m}-T_{p}\right)+\lambda\left\{\sum_{i=1}\left(T_{m}-T_{a}\right) \Delta t_{i}\right\}$

$\mathrm{Ng}$ etal. [2008] stated that a constant time interval of 5 minutes is sufficient enough to obtain fairly accurate results.

\section{Computation of $\lambda$}

The value of $\lambda$ is calculated for each experimental concrete mix using Equation (7) and the results obtained are tabulated in Table 3. The adiabatic temperature profile for each mix estimated using Equation (8) is illustrated in Figure 3.

Table 3 - Values of $\lambda$

\begin{tabular}{|c|c|}
\hline Mix & $\lambda$ \\
\hline M1-C & 0.0306 \\
\hline M2-C-F-20 & 0.0302 \\
\hline M3-C-F-35 & 0.0312 \\
\hline M4-C-A-1 & 0.0366 \\
\hline M5-C-A-2 & 0.0322 \\
\hline M6-C-A-F-20 & 0.0339 \\
\hline
\end{tabular}

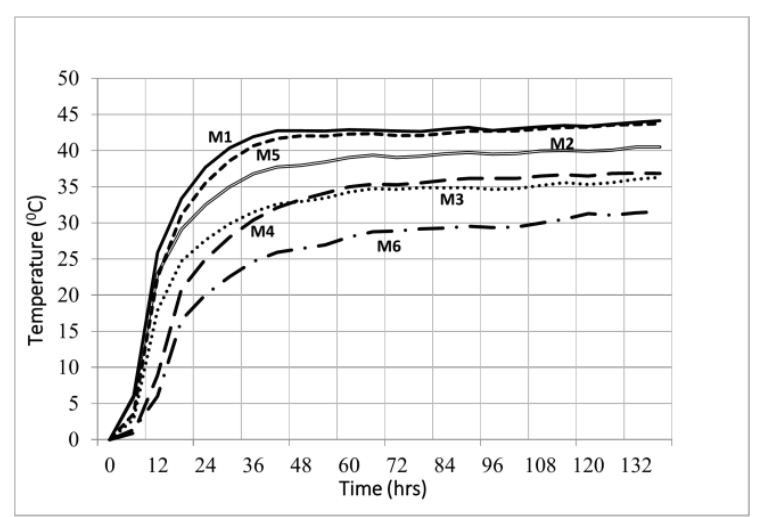

Figure 3 - Adiabatic temperature predictions

According to Figure 3, Mix 1 which comprised of the highest cement content shows the highest temperature rise. The results for Mix 2 and Mix 3 indicate that the higher the replacement level of Class F fly ash, the lesser is the adiabatic temperature rise. The maximum temperature rise of each of these two mixes is lower than that of Mix 1 by $3.9^{\circ} \mathrm{C}$ and $6.2{ }^{\circ} \mathrm{C}$ respectively. The resulting temperature rise of Mix 4 is lower than that of Mix 1 by $7.3{ }^{\circ} \mathrm{C}$ as the water reducing admixture reduced the cement content. The comparison of the results of Mix 1 and Mix 5 indicates that the mere addition of a water reducing admixture will not lower the heat of hydration of concrete. Mix 6 displays the least temperature rise, which is lower than that of Mix 1 by $11.6^{\circ} \mathrm{C}$.

\section{Prediction of Internal Concrete Temperature}

The Finite Difference Method (FDM) is preferred to be used along with the temperature prediction model since the FDM is comparatively a less complex and powerful tool to work with regular shape elements[Ballim 2004, Peir 2005]. Besides, FDM is easy to implement in computer programs.

\subsection{Determination of Nodal Equations using the Finite Difference Method}

For sections which have their $z$ dimension significantly larger than the $x$ and $y$ dimensions, it is fair to assume that the heat transfer along $z$ direction is negligible. This is a reasonable assumption for long walls and columns except near their top and bottom ends [Browne 2005]. The heat transfer across the member expressed in Equation (1) thus can be simplified into a two dimensional form as indicated below.

$$
\rho C \frac{\partial \mathrm{T}}{\partial \mathrm{t}}=k\left(\frac{\partial^{2} \mathrm{~T}}{\partial \mathrm{x}^{2}}+\frac{\partial^{2} \mathrm{~T}}{\partial \mathrm{y}^{2}}\right)+\frac{\partial \mathrm{Q}}{\partial \mathrm{t}}
$$


In Equation 9, it is further assumed that the thermal conductivity of concrete in the $x$ and $y$ directions is similar making $k_{x}=k_{y}=k$. In addition, $k$ is considered to be a constant within the selected time interval [Robbins 2007].

Finite differences are used to approximate differential increments in temperature and space coordinates. Temperature predictions will be much closer to the true values if the finite increments are small [Holmen 1986]. Thus, Ballim [2004] workedout the temperatures of six distinct nodes having $(\mathrm{m}, \mathrm{n})$ coordinates at time $(p+1)$ so that they can be expressed relative to the nodal temperature at time (p) as indicated below. The coordinates are selected such that $\Delta \mathrm{x}=\Delta \mathrm{y}=\Delta$.

\section{Centre node:}

$\mathrm{T}^{\mathrm{p}+1}{ }_{\mathrm{m}, \mathrm{n}}=\left(1-4 \mathrm{~F}_{0}\right) \mathrm{T}_{\mathrm{m}, \mathrm{n}}^{\mathrm{p}}+\mathrm{F}_{0}\left(\mathrm{~T}_{\mathrm{m}+1, \mathrm{n}}^{\mathrm{p}}+\mathrm{T}^{\mathrm{p}}{ }_{\mathrm{m}-1, \mathrm{n}}+\right.$

$\left.\mathrm{T}^{\mathrm{p}}{ }_{\mathrm{m}, \mathrm{n}+1}+\mathrm{T}_{\mathrm{m}, \mathrm{n}-1}^{\mathrm{p}}\right)+\frac{\Delta \mathrm{t}}{\rho \mathrm{C}} \frac{\partial \mathrm{Q}}{\partial \mathrm{t}}$

where,

Fourier number $\mathrm{F}_{0}=\frac{\alpha \Delta \mathrm{t}}{\Delta^{2}}, \alpha=\frac{k}{\rho C}$ and $\Delta \mathrm{t} \leq \rho \mathrm{C} \frac{\Delta^{2}}{4 k}$

Side surface node:

$\mathrm{T}_{\mathrm{m}, \mathrm{n}}^{\mathrm{p}+1}=\left(1-\mathrm{F}_{0}\left(4+2 \mathrm{Bi}_{\mathrm{y}}\right)\right) \mathrm{T}_{\mathrm{m}, \mathrm{n}}^{\mathrm{p}}+\mathrm{F}_{0}\left(2 \mathrm{~T}_{\mathrm{m}-1, \mathrm{n}}^{\mathrm{p}}+\right.$

$\left.\mathrm{T}^{\mathrm{p}}{ }_{\mathrm{m}, \mathrm{n}-1}+\mathrm{T}^{\mathrm{p}}{ }_{\mathrm{m}, \mathrm{n}+1}+2 \mathrm{Bi}_{\mathrm{y}} \mathrm{T}_{\mathrm{a}}^{\mathrm{p}}\right)+\frac{\Delta \mathrm{t}}{\rho \mathrm{C}} \frac{\partial \mathrm{Q}}{\partial \mathrm{t}}$

Where $\mathrm{Bi}_{\mathrm{y}}$ is the Biot number pertaining to horizontal heat transfer (perpendicular to they direction)through convection such that

$$
\mathrm{Bi}_{\mathrm{y}}=\frac{h_{y} \Delta}{k}
$$

$h_{y}$ is the pertaining heat transfer coefficient, $T_{a}$ is the surrounding temperature, and $\Delta \mathrm{t} \leq \frac{\rho \mathrm{C} \Delta^{2}}{\left(4+2 \mathrm{Bi}_{\mathrm{y}}\right) \mathrm{k}}$

Top surface node:

$\mathrm{T}^{\mathrm{p}+1}{ }_{\mathrm{m}, \mathrm{n}}=\left(1-\mathrm{F}_{0}\left(4+2 \mathrm{Bi}_{\mathrm{x}}\right)\right) \mathrm{T}_{\mathrm{m}, \mathrm{n}}^{\mathrm{p}}+\mathrm{F}_{0}\left(2 \mathrm{~T}_{\mathrm{m}-1, \mathrm{n}}^{\mathrm{p}}+\right.$

$\left.\mathrm{T}^{\mathrm{p}}{ }_{\mathrm{m}, \mathrm{n}-1}+\mathrm{T}^{\mathrm{p}}{ }_{\mathrm{m}+1, \mathrm{n}}+2 \mathrm{Bi}_{\mathrm{x}} \mathrm{T}^{\mathrm{p}}{ }_{\mathrm{a}}\right)+\frac{\Delta \mathrm{t}}{\rho \mathrm{C}} \frac{\partial \mathrm{Q}}{\partial \mathrm{t}}$

whereBi $\mathrm{x}_{\mathrm{x}}=\frac{h_{x} \Delta}{k}$ and $\Delta \mathrm{t} \leq \frac{\rho \mathrm{C} \Delta^{2}}{\left(4+2 \mathrm{Bi}_{\mathrm{x}}\right) \mathrm{k}}$

\section{Bottom surface node:}

$\mathrm{T}^{\mathrm{p}+1}{ }_{\mathrm{m}, \mathrm{n}}=\left\{1-\mathrm{F}_{0}\left(4+\frac{2 \mathrm{k}_{\mathrm{b}}}{\mathrm{k}}\right)\right\} \mathrm{T}^{\mathrm{p}}{ }_{\mathrm{m}, \mathrm{n}}+\mathrm{F}_{0}\left(2 \mathrm{~T}^{\mathrm{p}}{ }_{\mathrm{m}-1, \mathrm{n}}+\right.$

$\left.\mathrm{T}^{\mathrm{p}}{ }_{\mathrm{m}, \mathrm{n}-1}+\mathrm{T}^{\mathrm{p}}{ }_{\mathrm{m}, \mathrm{n}+1}+\frac{2 \mathrm{k}_{\mathrm{b}} \mathrm{T}_{\mathrm{b}}^{\mathrm{p}}}{\mathrm{k}}\right)+\frac{\Delta \mathrm{t}}{\rho \mathrm{C}} \frac{\partial \mathrm{Q}}{\partial \mathrm{t}}$

where $k_{b}$ is the thermal conductivity of the base material, $\mathrm{T}_{\mathrm{b}}^{\mathrm{p}}$ is the base temperature at time $\mathrm{p}$ and $\Delta \mathrm{t} \leq \frac{\rho \mathrm{C} \Delta^{2}}{4 \mathrm{k}+2 \mathrm{k}_{\mathrm{b}}}$

\section{Top corner node:}

$$
\begin{aligned}
& \mathrm{T}^{\mathrm{p}+1}{ }_{\mathrm{m}, \mathrm{n}}=\left\{1-F_{0}\left(4+\left(\mathrm{Bi}_{\mathrm{x}}+\mathrm{Bi}_{\mathrm{y}}\right)\right)\right\} \mathrm{T}^{\mathrm{p}}{ }_{\mathrm{m}, \mathrm{n}}+2 F_{0}\left(2 \mathrm{~T}^{\mathrm{p}}{ }_{\mathrm{m}, \mathrm{n}-1}+\right. \\
& \left.2 \mathrm{~T}^{\mathrm{p}}{ }_{\mathrm{m}+1, \mathrm{n}}+\left(\mathrm{Bi}_{\mathrm{x}}+\mathrm{Bi}_{\mathrm{y}}\right) \mathrm{T}^{\mathrm{p}}{ }_{\mathrm{a}}\right)+\frac{\Delta \mathrm{t}}{\rho \mathrm{C}} \frac{\mathrm{QQ}}{\partial \mathrm{t}} \\
& \text { where } \Delta \mathrm{t} \leq \frac{\rho \Delta^{2}}{\left(4+\left(\mathrm{Bi}_{\mathrm{x}}+\mathrm{Bi}_{\mathrm{y}}\right)\right) k}
\end{aligned}
$$

\section{Bottom corner node:}

$\mathrm{T}^{\mathrm{p}+1}{ }_{\mathrm{m}, \mathrm{n}}=\left\{1-F_{0}\left(4+2 \mathrm{Bi}_{\mathrm{y}}+\frac{k_{b}}{k}\right)\right\} \mathrm{T}_{\mathrm{m}, \mathrm{n}}^{\mathrm{p}}+2 F_{0}\left(2 \mathrm{~T}_{\mathrm{m}, \mathrm{n}+1}^{\mathrm{p}}+\right.$

$\left.2 \mathrm{~T}^{\mathrm{p}}{ }_{\mathrm{m}+1, \mathrm{n}}+\frac{\mathrm{T}_{\mathrm{b}} \mathrm{k}_{\mathrm{b}}}{\mathrm{k}}+\frac{2 \mathrm{~h}_{\mathrm{y}} \Delta \mathrm{xT}^{\mathrm{p}} \mathrm{a}}{\mathrm{k}}\right)++\frac{\Delta \mathrm{t}}{\rho \mathrm{C}} \frac{\partial \mathrm{Q}}{\partial \mathrm{t}}$

Where $\Delta \mathrm{t} \leq \frac{\rho \mathrm{C} \Delta^{2}}{\left(4+2 \mathrm{Bi} i_{\mathrm{y}}+\frac{k_{b}}{k}\right) k}$

More elaboration on the formation of these formulae can be found elsewhere [Ballim 2004, Wasala 2014].

\section{Formation of the 2D Temperature Prediction Model}

All of the equations derived above were written using Visual Basic and were linked with MS Excel software. The time dependent variables of the above equations such as the heat generation rate $\left(\frac{\partial Q}{\partial \mathrm{t}}\right)$, thermal conductivity of concrete during $\mathrm{p}^{\text {th }}$ time interval $(k)$, specific heat of concrete during $\mathrm{p}^{\text {th }}$ time interval $(C)$, and the temperature of air at $\mathrm{p}^{\text {th }}$ time interval $\left(\mathrm{T}^{\mathrm{p}}{ }_{\mathrm{a}}\right)$ are modelled separately as indicated below and incorporated into the prediction model. Further details on this are found in Wasala 2014.

\subsection{Heat Generation Rate}

The time-based heat generation rate was calculated from the predicted adiabatic temperature profiles. It was assumed that in the semi adiabatic calorimeter test, the chemical reaction, rate and extent of hydration were to a high extent, similar to the actual condition [Ballim 2004].Therefore, the time based heat rate was considered as reasonable for the prediction model used in this study. To achieve better accuracy, maturity based heat rate could be used for temperature prediction [Ballim and Graham 2003, Ballim 2004].

\subsection{Thermal Conductivity}

\subsubsection{Concrete}

Thermal conductivity of hardening concrete $(k)$ can be predicted from the ultimate thermal conductivity $\left(\mathrm{k}_{\mathrm{uc}}\right)$ as given below[Browne 2005].

$k(\infty)=k_{\mathrm{uc}}(1.33-0.33 \infty)$ 
Where $k(\infty)$ denotes the concrete thermal conductivity at ' $\infty$ ' degree of hydration.

The degree of hydration $(\infty)$ can be defined as the ratio between the quantity of hydrated cementitious material and the original quantity of cementitious material in the mix. VanBreugel [1991] stated that heat released at a given time $\left(\mathrm{H}_{\mathrm{t}}\right)$ divided by the total heat available $\left(\mathrm{H}_{\mathrm{T}}\right)$ provides a good measure of the degree of hydration as indicated below.

$\infty=\mathrm{H}_{\mathrm{t}} / \mathrm{H}_{\mathrm{T}}$

\subsubsection{Base Material}

Rock and soil were considered as base materials in this study. Thermal conductivities of rock and top soil were taken as $1.2 \mathrm{~W} / \mathrm{m} . \mathrm{k}$ and $0.52 \mathrm{~W} / \mathrm{m} . \mathrm{k}$ respectively[Browne2005].

\subsection{Base Temperature}

Base temperature $\left(\mathrm{T}_{\mathrm{b}}\right)$ is also a variable. If base type is selected as rock, $\mathrm{T}_{\mathrm{b}_{\mathbf{r}} \mathrm{r}}$ will be taken as the minimum temperature that occurred during the previous day. This is because the response of rock to variation of ambient temperature is less due to the absence of direct solar radiation [Ballim2004]. When the base is selected as soil, as proposed by [Browne 2005], base temperature $\mathrm{T}_{\mathrm{b}_{-} \mathrm{s}}$ can be calculated from,

$\mathrm{T}_{\mathrm{b} \_\mathrm{s}}=0.83 \mathrm{AAT}+3.7$

where AAT denotes the average annual temperature.

\subsection{Specific Heat of Concrete $(C)$}

The specific heat of concrete $(C)$ depends on the mix proportions $(m)$, specific heat of each constituent (c), degree of hydration $(\infty)$, temperature and moisture level. As proposed by [Browne 2005], it can be calculated from,

$$
C=\frac{\left(m_{c} \infty C_{\mathrm{ref}}+m_{c}(1-\infty) c_{c}+m_{a} c_{a}+m_{w} c_{w}\right)}{\rho_{\text {con }}}
$$

where $C_{\text {ref }}$ is the fictitious specific heat of the hydrating cement obtained from,

$$
C_{\text {ref }}=8.4 T_{\mathrm{c}}+339
$$

$T_{\mathrm{c}}$ and $\rho_{\text {con }}$ denote concrete temperature and concrete density respectively. Also, subscripts $c, a$ and $w$ represent cement, aggregate and water respectively.

Concrete density $\left(\rho_{\text {con }}\right)$ was measured and the results obtained are tabulated in Table 2.
As mentioned before, both $k$ and Chave beenassumed to be constant during the selected time interval. With increasing degree of hydration, corresponding values of those were calculated and assigned to the respective time steps in the predictor program.

\subsection{Formwork Convection Coefficient (h) and Curing Methods}

Two types of formwork material, namely steel and plywood were considered for the model. As proposed by Ballim [2004], the convection coefficients $(h)$ of these materials were taken as $8 \mathrm{~W} / \mathrm{m}^{2} .{ }^{\circ} \mathrm{C}$ and $4 \mathrm{~W} / \mathrm{m}^{2} .{ }^{0}$ Crespectively. For calculating $h$, the equations $h=8 \mathrm{~W} / \mathrm{m}^{2}{ }^{\circ}$ Cwas used for the exposed concrete surface and $h=31 \mathrm{~W} / \mathrm{m}^{2} .{ }^{\circ} \mathrm{C}$ was used when there was water curing.

\subsection{Ambient Temperature}

The temperature prediction model was associated with an approximate ambient temperature $\left(\mathrm{T}_{\mathrm{a}}^{\mathrm{p}}\right.$ ) at any time $\left(\mathrm{t}_{\mathrm{p}}\right)$ using only the daily maximum temperature $\left(\mathrm{T}_{\max }\right)$ and minimum temperature $\left(\mathrm{T}_{\min }\right)$ [Ballim 2004].

$$
\left.\mathrm{T}_{\mathrm{a}}{ }_{\mathrm{a}}=\frac{\mathrm{T}_{\max }+\mathrm{T}_{\min }}{2}+\sin \left[\frac{\pi}{12}\left(\mathrm{t}_{\mathrm{p}}+\mathrm{t}_{\mathrm{m}}\right)\right] \cdot \frac{\mathrm{T}_{\max }-\mathrm{T}_{\min }}{2}\right) \ldots
$$

wheret $_{\mathrm{m}}$ is the time when the minimum temperature occurs on the given day.

It is of note that while conducting the semiadiabatic calorimeter test, a thermocouple was also attached to measure the ambient temperature. Compatibility between the measured temperatures and Equation 21 predictions are found to be reasonable. Further details are found in Wasala[2014\}.

\section{Prediction Model Verification}

The temperature prediction model was verified with the results of an experimental investigation conducted by Nanayakkara and Wannigama [2003]. They had investigated the internal temperature rise of a Grade 35A, $1.0 \mathrm{~m}$ thick, $1.2 \mathrm{~m}$ high and $1.2 \mathrm{~m}$ long concrete block. The end faces of the block had been insulated with $25 \mathrm{~mm}$ thick expanded polystyrene to minimize the heat loss per pendicular to the formwork. 
The mix proportion used by Nanayakkara and Wannigama[2003] is not similar to any of the six C35A mixes used in the current study, though it reasonably represents the average conditions of M1 and M4. Therefore, the temperature of the concrete block was predicted using M1 and M4 adiabatic profiles along with other relevant inputs and the maximum temperature rise was predicted to be $39.1^{\circ} \mathrm{C}$ and $29.8^{\circ} \mathrm{Crespectively.} \mathrm{The} \mathrm{average} \mathrm{of}$ these two values, which is $34.45^{\circ} \mathrm{C}$, fairly agrees with the measured temperature rise of $32.5^{\circ} \mathrm{C}$. The suitability of the temperature prediction model was thus reasonably verified. Further verification on a wide range of experimental results is a matter for future work. More details of this validation can be found in Wasala [2014].

\section{Case study}

The prediction model can be used to carry out parametric studies to examine temperature development in concrete. For instance, as a case study, the peak temperature vs. thickness behaviour of a $2 \mathrm{~m}$ high concrete wall cast on a rock base with $12 \mathrm{~mm}$ thick plywood side formwork was observed. It was assumed that concrete placing temperature was $30^{\circ} \mathrm{C}$, time was 9 a.m., and formwork striking time was $40 \mathrm{~h}$, continuous water curing was applied and the day temperature varied between $25^{\circ} \mathrm{C}$ and $35^{\circ} \mathrm{C}$.

The behaviour was studied for all C35A concrete mixes except for Mix 5 and the results obtained are illustrated in Figure 4. Mix 5 was excluded since it was found previously that Mix 5 behaviour was similar to that of Mix 1 .

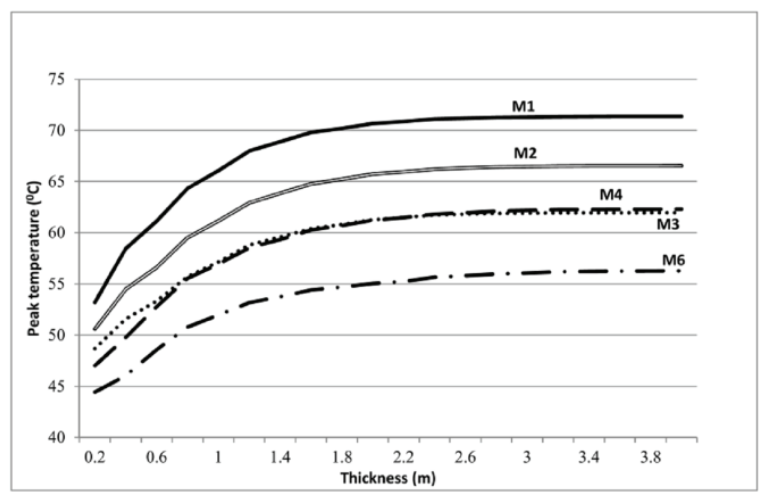

Figure 4 - Temperature vs. concrete thickness behaviour

As shown in Figure 4, the thicker the section, the greater is the peak temperature, but beyond about a thickness of $1.8 \mathrm{~m}$, the increase in temperature becomes negligible in each mix.
The highest temperature rise was noted in the OPC mix (M1) which is about $72^{\circ} \mathrm{C}$, the use of $20 \%$ fly ash results in a maximum temperature of about $66^{\circ}$ Cand the use of $35 \%$ fly ash results in a further reduction in the peak temperature. As anticipated, mix M6 comprised of fly ash and the admixture brings the lowest temperature escalation which is about $56^{\circ} \mathrm{C}$.

Amongst the numerous causes for temperature associated concrete cracking, delayed ettringite formation plays a major role. A peak temperature of $70{ }^{\circ} \mathrm{C}$ has been stipulated for concrete sections to prevent delayed ettringite formation [Taylor 2001]. As an important conclusion of this case study, it can be noted that when the thickness exceeds $1.6 \mathrm{~m}$, the OPC concrete (M1 mix) exceeds this particular threshold temperature. However, this threshold temperature is not reached for any thickness in the other mixes, so is highlighted that with the appropriate use of fly ash and water reducing admixtures, the temperature rise in structures can be controlled to desired levels. Thus, the prediction model can be used to study the various trends in the temperature development in concrete and to take appropriate remedial measures.

\section{Conclusions}

The study focussed on two key areas, namely the prediction of adiabatic temperature rise of six distinct C35A concrete mixes using semiadiabatic temperature measurements; and the development of a temperature prediction model. The following conclusions can be drawn from the study.

1. An increase in the amount of Class F fly ash lowers the temperature rise. The use of $20 \%$ and $35 \%$ Class $\mathrm{F}$ fly ash lowers the maximum semi-adiabatic temperature rise by $4^{\circ} \mathrm{C}$ and $6^{\circ} \mathrm{C}$ respectively from the concrete without fly ash. The maximum adiabatic temperature rise also decreases by $4^{\circ} \mathrm{C}$ and $7.5^{\circ} \mathrm{C}$ respectively.

2. The concrete mix comprising of cement, fly ash, and admixture indicates the lowest peak temperature rise (M6-C-A-F-20). The maximum semi-adiabatic temperature rise for this mix is lower than that for the control mix (M1-C) by $12{ }^{\circ} \mathrm{C}$.

3. The temperature prediction model composed with finite difference techniques and concrete adiabatic temperature rise is a 
useful tool to predict the internal temperature of concrete.

4. The prediction model can be used to conduct numerous case studies. Such a study was carried out to examine the temperature rise vs. thickness behaviour of a $2 \mathrm{~m}$ high concrete wall under certain fixed conditions. The study proves that when OPC is used, the maximum thickness that will prevent delayed ettringite formation is $1.6 \mathrm{~m}$. It further reveals that greater thicknesses than that can be achieved with the alteration of the mix design with fly ash and water reducing admixtures appropriately.

\section{Acknowledgements}

Special thanks go to Mr. H. Aberuwan for providing numerous technical advices. The first author would like to acknowledge the commendable support given by the Materials Laboratory staff of the University of Peradeniya, especially Mr. G.N. Laksiri and Mr. E.G.M. Munaweera. The first author is also grateful for the financial support provided by the National Water Supply and Drainage Board (NWSDB) to conduct the study.

\section{References}

1. Ballim, Y., "A Numerical Model and Associated Calorimeter for Predicting Temperature Profiles in Mass Concrete", Cement $\mathcal{E}$ Concrete Composites, Vol.26, 2004, pp. 695-703.

2. Browne, R., Concrete Works Version 2.0 User Manual, Concrete Durability Center, Department of Transportation, Texas, 2005.

3. Holmen, J. P., Heat Transfer, $6^{\text {th }}$ ed., McGrawHill, Singapore,1986.
4. Morabito, P." "Adiabatic and Semi-adiabatic Calorimetric to Determine the Temperature Increase in Concrete due to Hydration Heat of the Cement" Materials and Structures, Vol. 30, 1997.

5. Ng, P. L., Ng, I. Y. T. and Kwan, A. K. H., “Heat Loss Compensation in Semi-adiabatic Curing Test of Concrete" ACI Materials Journal, Vol.105, No.1, 2008, 52-61.

6. Neville, A. M. and Brooks, J. J., Concrete Technology, Longman, Essex, 1987.

7. Taylor, H. F. W., Famy, C. and Scrivener, K. L., Delayed Ettringite Formation, Cement and Concrete Research, Vol.31, No.5, 2001, 683-693.

8. VanBreugel, K., Simulation of Hydration and Formation of Structure in Hardening Cement Based Materials, PhD Dissertation, Civil Engineering and Geo Sciences, Delft, 1991.

9. Wasala, W. M. T. D., Prediction of Heat Development in Concrete using Semi-adiabatic Temperature Measurements, MEng Dissertation, University of Peradeniya, Sri Lanka., 2014.

10. Kyle, A. R., Jonathan, L. P., Anton, K. S., Maria, C. G. J. and Kevin, J. F., "Evaluation of Temperature Prediction Methods for Mass Concrete Members", ACI Materials Journal, Vol. 103, No. 5, 2006, pp.357-365.

11. Ballim, Y. and Graham, P. C., "A Maturity Approach to the Rate of Heat Evolution in Concrete", Magazine of Concrete Research, Vol. 55, No. 3, 2003, pp. 249-256.

12. Nanayakkara, S. M. A. and Wannigama, W. R. K., "Experimental Investigation on Temperature Rise due to Heat of Hydration", Annual Transactions of IESL, 2003, pp. 9-15. 